\title{
FITOSSOCIOLOGIA DE DOIS TRECHOS DE FLORESTA OMBRÓFILA DENSA ALUVIAL EM SOLOS HIDROMÓRFICOS, PARANÁ, BRASIL
}

\author{
Renata Ribas Zacarias ${ }^{1}$; Ricardo Miranda de Britez ${ }^{2}$; Franklin Galvão ${ }^{3}$; Maria Regina Torres Boeger ${ }^{4}$ \\ ${ }^{1}$ Bióloga, M.Sc., Ecologia e Conservação, UFPR, Curitiba, PR, Brasil - renata.ribasz@ gmail.com \\ ${ }^{2}$ Biólogo, Dr. em Engenharia Florestal, SPVS, Curitiba, PR, Brasil - cachoeira@spvs.org.br \\ ${ }^{3}$ Eng. Florestal, Dr., Prof. do Depto. de Ciências Florestais, UFPR, Curitiba, PR, Brasil - fgalvao@ufpr.br \\ ${ }^{4}$ Bióloga, Dr ${ }^{\mathrm{a}}{ }_{2}$ Depto. de Botânica, UFPR, Curitiba, PR Brasil - rboeger@ufpr.br \\ Recebido para publicação: 29/12/2010 - Aceito para publicação: 06/11/2012
}

\begin{abstract}
Resumo
O presente estudo teve por objetivo caracterizar a estrutura de dois trechos de Floresta Ombrófila Densa Aluvial localizados no município de Guaraqueçaba, Paraná. Os aspectos vegetacionais foram relacionados a características ambientais como solos, relevo e profundidade do lençol freático. Para o levantamento fitossociológico foram alocadas 16 parcelas de $10 \times 10 \mathrm{~m}$ em cada trecho estudado e amostradas todas as árvores com Perímetro à Altura do Peito $\geq 15 \mathrm{~cm}$. Ambas as áreas apresentaram uma associação entre Gleissolo Háplico e Gleissolo Melânico. No total foram identificadas 81 espécies, incluídas em 59 gêneros e 31 famílias. Myrtaceae foi a família de maior riqueza em ambos os compartimentos. O índice de similaridade de Jaccard foi de 29,6\%. O índice de diversidade de Shannon ( $\left.H^{\prime}\right)$ foi maior para o trecho de menor saturação hídrica $\left(H^{\prime}=3,13\right)$. Para o trecho de maior saturação hídrica $H^{\prime}$ foi igual a 2,86 visto que poucas espécies são bem adaptadas aos solos temporariamente ou permanente saturados por água. Em razão da proximidade geográfica e das similaridades climáticas e pedológicas existentes entre os sítios estudados, concluiu-se que as diferenças estruturais e florísticas constatadas estão associadas às condições hídricas do substrato.

Palavras-chave: Mata Atlântica; planície litorânea; caxeta; saturação hídrica.
\end{abstract}

\begin{abstract}
Phytosociology analysis of two sites in the Dense Alluvial Ombrophilous Forest with hydromorphic soils, Paraná, Brazil. In the present study, we characterize the structure in two sites of Dense Alluvial Ombrophilous Forest, Guaraqueçaba, State of Paraná, Brazil. Aspects of the vegetation were associated to environmental conditions such as soils, topography and water table depth. For the phytosociological study, 16 plots of $10 \times 10 \mathrm{~m}$ were established in each site and all trees with Perimeter at breast height $\geq 15 \mathrm{~cm}$ were sampled. Both sites presented a mixture of Haplic Gleisoil and Melanic Gleisoil. A total of 81 species were identified, belonging to 59 genera and 31 families. Myrtaceae was the family of greatest richness in both areas. The Jaccard's similarity index was $29,6 \%$. The Shannon's diversity index was lower in the site of greater water saturation $\left(H^{\prime}=2,86\right)$. However, few species are well adapted to environmental constraints associated with excess water in the substrate. Due to geographical proximity and similarities of climate and soil between the communities, the main factor determining the structure and floristic composition seems to be closely related to the condition of drainage of the soil.

Keywords: Atlantic Forest; coastal plain; caxeta; water saturation.
\end{abstract}

\section{INTRODUCAO}

O complexo conjunto de formações vegetais que constitui o bioma Mata Atlântica é a expressão de múltiplas variáveis condicionantes como, história geológica, relevo, características pedológicas, vegetação adjacente, interferência antrópica, fatores climáticos, entre outras. São características de destaque deste bioma a grande diversidade de formas biológicas e o elevado endemismo de espécies, além da inestimável importância de seus serviços ambientais, como por exemplo, a manutenção da 
qualidade dos recursos hídricos, da integridade dos solos e fixação de carbono tanto na biomassa quanto no substrato.

Dentre as diversas formações vegetacionais do bioma Mata Atlântica tem-se a Floresta Ombrófila Densa que se distribui do Rio Grande do Norte até o Rio Grande do Sul (FRANKE et al., 2005). Esta unidade fitogeográfica apresenta-se formada por um mosaico vegetal resultante, principalmente, de variações de solos e de altitude (FERNANDES, 2003).

O processo de devastação da vegetação do bioma Mata Atlântica teve início nas áreas costeiras, sendo mais acentuado nas áreas de planície, em especial nas zonas próximas aos rios, o que resultou na quase total transformação desses ambientes. No Paraná, as planícies aluviais costeiras, que correspondem a Floresta Ombrófila Densa Aluvial, continuam sendo exploradas e fortemente ameaçadas em decorrência, principalmente da expansão da atividade agropecuária (SECRETARIA MEIO AMBIENTE DO ESTADO DO PARANÁ (SEMA), 2002).

Considerando o processo de devastação das florestas de planície e a escassez de informações sobre a ecologia destes ambientes, é de suma importância o desenvolvimento de estudos que permitam aprofundar o conhecimento sobre sua biota e as relações com o meio físico.

Na planície litorânea os principais fatores que afetam as características da vegetação são a drenagem do substrato resultante da elevação e da redução do nível do lençol freático e as formas de relevo aliados a composição do sedimento que condicionam a formação e evolução do solo (ROSSI; QUEIROZ NETO, 2001).

A ocorrência de determinada tipologia florestal (composição florística e estrutura) em solos hidromórficos, tem sido estudada por diversos autores, sendo condicionada a fatores como diversidade topográfica (IVANAUSKAS et al., 1997; MARQUES et al., 2003), influência do lençol freático (ARAUJO et al., 2004; BARDDAL et al., 2004; TONIATO et al., 1998) e drenagem do solo (CURCIO et al., 2006; BIANCHINI et al., 2003; TEIXEIRA; ASSIS, 2005).

Pouco se sabe sobre a distribuição das espécies arbóreas em relação às características ambientais, considerando uma pequena escala espacial (TEIXERA; ASSIS, 2009) e em especial a Floresta Ombrófila Densa Aluvial (FDA) do litoral do Paraná. Este trabalho objetivou caracterizar a estrutura de dois trechos com fitofisionomias distintas desta formação e analisar as relações existentes entre a vegetação e o meio físico, com ênfase em solos, relevo e nível de lençol freático.

\section{MATERIAL E MÉTODOS}

As áreas de estudo estão localizadas na Reserva Natural Serra do Itaqui (RNSI), município de Guaraqueçaba, litoral norte do estado do Paraná (SOCIEDADE DE PESQUISA EM VIDA SELVAGEM E EDUCAÇÃO AMBIENTAL (SPVS), 2006). Nesta região se concentram alguns dos poucos remanescentes florestais bem conservados da Floresta Ombrófila Densa (FERNANDES, 2003).

A classificação do clima segundo Köeppen é Af pluvial tropical de transição (t), com fraco período seco e rara ocorrência de geadas (MAACK, 1981). De acordo com as médias históricas obtidas entre os anos de 1978 a 2011 na estação climática de Guaraqueçaba do Instituto Agronômico do Paraná, o mês mais chuvoso foi janeiro com precipitação média de $407 \mathrm{~mm}$ e o mais seco foi agosto com precipitação média de 87 mm (INSTITUTO AGRONÔMICO DO PARANÁ (IAPAR), 2012).

Nas áreas de planície, composta de rochas graníticas do embasamento cristalino, predominam os depósitos sedimentares quaternários de origem continental (alúvio-coluvionar) ou costeira (ROCHA et al., 2002a), sendo comum os Gleissolos e Neossolos Flúvicos (ROCHA et al., 2002b).

As principais fitofisionomias encontradas são: Formações Pioneiras de Influência Fluvial e Flúvio-marinha, Floresta Ombrófila Densa das Terras Baixas, Aluvial e Submontana, além dos sistemas de ocupação secundária resultantes da alteração parcial ou total da vegetação original (BORGO, 2004).

O levantamento fitossociológico foi realizado através do método de parcelas contíguas de $10 \mathrm{x}$ $10 \mathrm{~m}$ (MULLER-DOMBOIS; ELLENBERG, 1974), reunidas em quatro blocos de quatro parcelas totalizando uma área de 0,16 ha em cada compartimento estudado (coordenadas X/Y - 757.719/7.200.777 e 757.608/7.200.647).

Todos os indivíduos arbóreos com perímetro a altura do peito (PAP equivalente a $1,30 \mathrm{~m} \mathrm{em}$ relação ao solo) igual ou superior a $15 \mathrm{~cm}$ foram amostrados, inclusive indivíduos mortos em pé e vivos 
deitados. Árvores bifurcadas tiveram todos os seus fustes medidos, desde que um deles atingisse o critério de inclusão.

A identificação taxonômica foi realizada por meio de análise e comparação com material dos herbários do Departamento de Botânica e da Escola de Florestas de Curitiba, ambos da Universidade Federal do Paraná (UFPR) e através do auxílio de especialistas de algumas famílias botânicas. A ordenação das famílias foi baseada em Souza e Lorenzi (2005).

Os parâmetros fitossociológicos considerados foram os comumente utilizados em levantamentos florestais quantitativos e calculados por meio do programa Fitopac 1.0 (SHEPERD, 1994). Para cada compartimento também foram determinados o índice de diversidade de Shannon $\left(\mathrm{H}^{\prime}\right)$, o índice de diversidade de Simpson (RICKLEFS, 2003) e o índice de equidade (PIELOU, 1975). Para avaliar a semelhança da composição florística entre os dois compartimentos, utilizou-se o índice de similaridade de Jaccard (MUELLER-DOMBOIS; ELLENBERG, 1974). Os valores de área basal, diâmetro médio e altura média obtidos em cada área de estudo foram comparados estatisticamente pelo teste de $t$ de Student $(\alpha=0,01)$. Através de observações visuais em campo foram identificados o número de estratos arbóreos de cada compartimento e definido o intervalo de altura em metros de cada estrato.

Para auxiliar na compreensão das condições topográficas dos dois compartimentos estudados, realizou-se um traçado do perfil do relevo a partir da utilização de instrumentos de simples medição.

Para tanto, fixou-se uma estaca em um ponto "zero" próximo à trilha coincidente com o início do primeiro grupo de parcelas. Estabeleceu-se um intervalo de $10 \mathrm{~m}$ para fixação de uma segunda estaca. Entre estes dois pontos esticou-se um cabo que ficou suspenso cerca de um metro do chão sendo mantido totalmente alinhado através da utilização de um nível. Com auxílio de uma trena mensurou-se a cada metro a altura entre o cabo e o chão. Este processo foi repetido sequencialmente ao longo da trilha até o ponto coincidente com o final do último conjunto de parcelas obtendo-se assim um desenho do relevo do terreno.

As variações no nível do lençol freático foram registradas a cada 10 dias durante os meses de fevereiro a junho de 2007. Para tanto, foi instalado um poço hídrico em cada bloco de quatro parcelas. Os poços foram confeccionados em tubos de PVC, com $120 \mathrm{~cm}$ de comprimento e $60 \mathrm{~mm}$ de diâmetro e perfurados a cada $10 \mathrm{~cm}$, em toda sua extensão.

Para caracterização do solo foram coletadas duas amostras de material, uma do horizonte A e outra do horizonte $\mathrm{Cg}$, em cada bloco de quatro parcelas. A cor dos horizontes foi determinada por meio de comparação com a carta Munsell Soil Color Company (1975), sendo também registradas suas espessuras. As amostras foram submetidas às análises físico-químicas de rotina realizadas nos Laboratórios de Física e de Fertilidade do Solo do Departamento de Solos e Engenharia Agrícola da UFPR, seguindo método preconizado pela Empresa Brasileira de Pesquisa Agropecuária (EMBRAPA), (1997). Os solos foram classificados de acordo com o Sistema Brasileiro de Classificação de Solos (SANTOS et al., 2006).

\section{RESULTADOS E DISCUSSÃO}

\section{Meio físico}

Os compartimentos estudados apresentam relevo plano. Todavia, é comum a presença de pequenas projeções formadas pelo acúmulo de sedimentos minerais ou orgânicos caracterizando um micro-relevo irregular. A diferença altimétrica entre as áreas foi de aproximadamente um metro, mas suficiente para configurar uma zona abaciada em um dos compartimentos, o que sugere a ocorrência de convergência hídrica.

O nível do lençol freático esteve mais próximo da superfície durante os meses de fevereiro e meados de março (verão), coincidindo com a estação climática de maior precipitação na região. Constatou-se, também, diferença de saturação hídrica entre os sítios, através do não afloramento do lençol freático em um dos trechos e afloramento periódico no outro (área de menor altitude). Assim, os trechos estudados passaram a ser denominados, compartimento mal drenado e compartimento muito mal drenado, respectivamente.

No compartimento muito mal drenado, observou-se que, mesmo no mês em que o lençol freático esteve mais profundo (junho) o solo permanecia encharcado e, durante os períodos de alagamento, favorecidos pelo micro-relevo, partes do substrato permaneciam emersas, representando pontos preferenciais para o desenvolvimento da vegetação. Esta condição também foi evidenciada por Sztutman 
e Rodrigues (2002) para a floresta de planície litorânea do estado de São Paulo e em mata de brejo do município de Campinas/SP por Toniato et al. (1998).

Os dois compartimentos apresentaram o substrato constituído de material mineral com processos de gleização dentro dos primeiros $50 \mathrm{~cm}$ da superfície do solo resultantes da escassez de oxigênio causada pelas restrições à drenagem (ROCHA et al., 2002b; CURCIO et al., 2006). Assim, em nível de ordem todas as parcelas tiveram substrato classificado como Gleissolo.

Três amostras do compartimento mal drenado e duas do compartimento muito mal drenado apresentaram horizonte A de tonalidade escura, com espessura aproximada de $25 \mathrm{~cm}$ (incluindo o horizonte transicional), moderadamente desenvolvido, saturação por bases inferior a $65 \%$ e teor de carbono insuficiente para caracterizá-los como húmico ou hístico, sendo classificados Gleissolos Melânicos com horizonte A proeminente (SANTOS et al., 2006).

Este horizonte superficial proeminente é resultante do acúmulo de matéria orgânica, no entanto, o recorrente abaixamento do lençol freático favorece a sua decomposição periódica, o que impede a evolução para horizontes mais ricos em carbono orgânico (RACHWAL; CURCIO, 2001).

As demais amostras, por não apresentarem uma espessura mínima de $25 \mathrm{~cm}$ do horizonte superficial, foram classificadas como Gleissolos Háplicos com horizonte A moderado (SANTOS et al., 2006). Portanto, o substrato dos compartimentos estudados, representa uma associação entre Gleissolo Háplico e Gleissolo Melânico. Os resultados das análises químicas podem ser observados na tabela 1.

Tabela 1. Resultados das análises químicas do solo analisado em dois compartimentos de Floresta Ombrófila Densa Aluvial, na Reserva Natural Serra do Itaqui, Guaraqueçaba, PR.

Table 1. Results of the chemical analysis of soil obtained from two sites in the Dense Alluvial Ombrophilous Forest of the Natural Reserve of Sierra Itaqui, Guaraqueçaba, State of Paraná.

\begin{tabular}{|c|c|c|c|c|c|c|c|c|c|c|c|c|c|}
\hline \multirow{2}{*}{ Am } & \multirow[b]{2}{*}{ Hor } & $\mathbf{A l}^{+3}$ & $\mathrm{H}^{+}+\mathrm{Al}^{+3}$ & $\mathrm{Ca}^{+2}$ & $\mathrm{Mg}^{+2}$ & $\mathbf{K}^{+}$ & $\mathbf{S}$ & $\mathbf{T}$ & \multirow{2}{*}{$\begin{array}{c}\mathrm{pH} \\
\mathrm{CaCl}_{2}\end{array}$} & \multirow{2}{*}{$\begin{array}{c}P \\
\mathrm{mg} / \mathrm{dm}^{3}\end{array}$} & \multirow{2}{*}{$\begin{array}{c}C \\
\mathrm{~g} / \mathrm{dm}^{3}\end{array}$} & \multirow{2}{*}{$\begin{array}{l}\mathrm{V} \\
\% \\
\end{array}$} & \multirow{2}{*}{$\begin{array}{l}\mathbf{m} \\
\%\end{array}$} \\
\hline & & \multicolumn{7}{|c|}{$\mathrm{cmol} / \mathrm{dm}^{3}$} & & & & & \\
\hline \multicolumn{14}{|c|}{ Compartimento mal drenado } \\
\hline \multirow[t]{2}{*}{$1 \mathrm{GM}$} & $\mathrm{A}$ & 4,9 & 16,3 & 1,0 & 1,2 & 0,28 & 2,48 & 18,78 & 3,8 & 5,2 & 37,7 & 13 & 66 \\
\hline & $\mathrm{Cg}$ & 9,8 & 19,0 & 0,3 & 0,8 & 0,19 & 1,29 & 20,29 & 3,8 & 3,0 & 10,6 & 6 & 88 \\
\hline \multirow[t]{2}{*}{ 2GM } & A & 5,8 & 24,5 & 0,3 & 0,8 & 0,24 & 1,34 & 25,84 & 3,7 & 6,2 & 51,0 & 5 & 81 \\
\hline & $\mathrm{Cg}$ & 10,1 & 20,4 & 0,4 & 0,3 & 0,18 & 0,88 & 21,28 & 3,8 & 1,2 & 6,3 & 4 & 92 \\
\hline \multirow{2}{*}{$3 \mathrm{GH}$} & A & 6,1 & 15,2 & 0,4 & 0,5 & 0,19 & 1,09 & 16,29 & 3,7 & 3,2 & 34,1 & 7 & 85 \\
\hline & $\mathrm{Cg}$ & 8,5 & 19,0 & 0,2 & 0,2 & 0,20 & 0,60 & 19,60 & 3,8 & 2,1 & 8,8 & 3 & 93 \\
\hline \multirow[t]{2}{*}{ 4GM } & A & 3,6 & 13,1 & 0,4 & 0,3 & 0,22 & 0,92 & 14,02 & 3,8 & 3,5 & 25,7 & 7 & 80 \\
\hline & $\mathrm{Cg}$ & 4,7 & 13,1 & 0,2 & 0,2 & 0,11 & 0,51 & 13,61 & 3,9 & 2,3 & 8,8 & 4 & 90 \\
\hline \multicolumn{14}{|c|}{ Compartimento muito mal drenado } \\
\hline \multirow[t]{2}{*}{$5 \mathrm{GH}$} & A & 4,7 & 19,0 & 0,5 & 0,6 & 0,21 & 1,31 & 20,31 & 3,4 & 8,5 & 49,8 & 6 & 78 \\
\hline & $\mathrm{Cg}$ & 5,6 & 15,2 & 3,6 & 2,8 & 0,19 & 6,59 & 21,79 & 3,9 & 1,5 & 19,0 & 30 & 46 \\
\hline \multirow[t]{2}{*}{$6 \mathrm{GM}$} & A & 2,8 & 22,5 & 0,8 & 0,1 & 0,22 & 1,12 & 23,62 & 3,4 & 9,8 & 60,6 & 5 & 71 \\
\hline & $\mathrm{Cg}$ & 6,2 & 24,5 & 0,2 & 0,4 & 0,08 & 0,68 & 25,18 & 3,6 & 3,2 & 58,8 & 3 & 90 \\
\hline \multirow[t]{2}{*}{$7 \mathrm{GH}$} & A & 2,4 & 20,6 & 0,2 & 0,6 & 0,28 & 1,08 & 21,68 & 3,5 & 12,9 & 59,4 & 5 & 69 \\
\hline & $\mathrm{Cg}$ & 5,2 & 14,1 & 0,6 & 1,7 & 0,24 & 2,54 & 16,64 & 3,9 & 3,5 & 17,2 & 15 & 67 \\
\hline \multirow[t]{2}{*}{$8 \mathrm{GM}$} & A & 3,6 & 16,3 & 0,2 & 0,5 & 0,19 & 0,89 & 17,19 & 3,6 & 7,6 & 74,2 & 5 & 80 \\
\hline & $\mathrm{Cg}$ & 6,2 & 20,6 & 0,1 & 0,2 & 0,08 & 0,38 & 20,98 & 3,7 & 2,5 & 52,8 & 2 & 94 \\
\hline
\end{tabular}

GM : Gleissolo Melânico com horizonte A proeminente; GH: Gleissolo Háplico com horizonte A moderado; Am: identificação do número da amostra; Hor: horizonte; S: soma de bases; T: capacidade de troca de cátions; V: saturação em bases; m: saturação em alumínio.

A composição granulométrica (Tabela 2) indicou ocorrência de depósitos de textura fina, dominantemente argilosos, provenientes do continente, ou seja, deposição alúvio-coluvionar.

\section{Vegetação do compartimento mal drenado}

Ao todo foram registrados 395 indivíduos (2.469 indivíduos/ha), distribuídos em 26 famílias, 44 gêneros e 57 espécies. A família Myrtaceae apresentou 17 espécies, sendo frequentemente considerada a família com maior diversidade de espécies em diferentes formações vegetais do bioma Mata Atlântica 
(OLIVEIRA-FILHO; FONTES, 2000; CARVALHO et al., 2008). Na tabela 3, estão registradas as variáveis fitossociológicas das 20 principais espécies amostradas.

Tabela 2. Resultados das análises granulométricas do solo analisado em dois compartimentos de Floresta Ombrófila Densa Aluvial, na Reserva Natural Serra do Itaqui, Guaraqueçaba, PR.

Table 2. Results from a particle size analysis of soil obtained from two sites in the Dense Alluvial Ombrophilous Forest of the Natural Reserve of Sierra Itaqui, Guaraqueçaba, State of Paraná.

\begin{tabular}{|c|c|c|c|c|c|c|}
\hline \multirow{2}{*}{$\begin{array}{l}\mathrm{N}^{\circ} \text { da } \\
\text { amostra }\end{array}$} & \multirow{2}{*}{ Horizonte } & \multicolumn{5}{|c|}{ Composição granulométrica $(\%)$} \\
\hline & & Areia grossa & Areia fina & Areia total & Silte & Argila \\
\hline \multicolumn{7}{|c|}{ Compartimento mal drenado } \\
\hline \multirow{2}{*}{$1 \mathrm{GM}$} & A & 0,20 & 1,80 & 2,00 & 38,00 & 60,00 \\
\hline & $\mathrm{Cg}$ & 0,15 & 1,45 & 1,60 & 33,40 & 65,00 \\
\hline \multirow{2}{*}{$2 \mathrm{GM}$} & $\mathrm{A}$ & 0,35 & 0,90 & 1,25 & 38,75 & 60,00 \\
\hline & $\mathrm{Cg}$ & 0,35 & 1,40 & 1,75 & 33,25 & 65,00 \\
\hline \multirow{2}{*}{$3 \mathrm{GH}$} & A & 0,85 & 7,20 & 8,05 & 41,95 & 50,00 \\
\hline & $\mathrm{Cg}$ & 0,60 & 11,75 & 12,35 & 32,65 & 55,00 \\
\hline \multirow{2}{*}{$4 \mathrm{GM}$} & A & 5,50 & 20,25 & 25,75 & 34,25 & 40,00 \\
\hline & $\mathrm{Cg}$ & 6,00 & 30,50 & 36,50 & 26,00 & 37,50 \\
\hline \multicolumn{7}{|c|}{ Compartimento muito mal drenado } \\
\hline \multirow{2}{*}{$5 \mathrm{GH}$} & A & 0,37 & 0,24 & 0,61 & 56,65 & 42,74 \\
\hline & $\mathrm{Cg}$ & 1,50 & 5,35 & 6,85 & 23,15 & 70,00 \\
\hline \multirow{2}{*}{$6 \mathrm{GM}$} & A & 0,25 & 0,08 & 0,33 & 57,65 & 42,02 \\
\hline & $\mathrm{Cg}$ & 0,45 & 0,35 & 0,80 & 39,20 & 60,00 \\
\hline \multirow{2}{*}{$7 \mathrm{GH}$} & A & 0,13 & 0,19 & 0,32 & 61,19 & 38,49 \\
\hline & $\mathrm{Cg}$ & 0,05 & 1,00 & 1,05 & 41,45 & 57,50 \\
\hline \multirow{2}{*}{$8 \mathrm{GM}$} & A & 0,20 & 0,10 & 0,30 & 39,70 & 60,00 \\
\hline & $\mathrm{Cg}$ & 0,15 & 0,20 & 0,35 & 34,65 & 65,00 \\
\hline
\end{tabular}

GM : Gleissolo Melânico com horizonte A proeminente; GH: Gleissolo Háplico com horizonte A moderado.

Pera glabrata e Psychotria nuda foram as espécies com maiores valores de importância e juntas respondem por $25,7 \%$ do valor total obtido para todas as espécies amostradas. Presente em todas as parcelas e com indivíduos de médio a grande porte, $P$. glabrata também apresentou o maior valor de cobertura dentre as espécies amostradas e mesmo tratando-se de uma espécie pioneira heliófita, é frequentemente encontrada no interior da floresta primária densa (LORENZI, 2002).

Apesar da baixa dominância, Psychotria nuda apresentou alta densidade e frequência, o que a manteve em segundo lugar em valor de importância. A terceira espécie em importância foi Psidium cattleianum, que está quase sempre presente nas áreas úmidas da restinga litorânea (LORENZI, 2002).

Calophyllum brasiliense e Tapirira guianensis, ambas com apenas quatro indivíduos, permaneceram entre as dez espécies de maior importância devido ao grande porte de seus exemplares. Estas espécies possuem ampla distribuição pelo Brasil, ocorrendo preferencialmente em terrenos úmidos (KLEIN, 1978; LORENZI, 2002; MARQUES; JOLY, 2000). Em matas de brejo localizadas no interior paulista, Calophyllum brasiliense apresentou o maior valor de importância, não somente devido ao porte de seus indivíduos, como também pelas suas elevadas densidade e frequência (IVANAUSKAS et al., 1997; TONIATO et al., 1998).

Syagrus romanzoffiana e Euterpe edulis são particularmente abundantes nos agrupamentos vegetais primários localizados em solos muito úmidos ou inundáveis (KLEIN, 1984; TONIATO et al. 1998; LORENZI, 2002). Neste estudo apresentaram densidade e frequência relativamente altas o que possibilitou que elas se mantivessem entre as dez espécies de maior importância. Para Euterpe edulis, foram encontrados resultados semelhantes ao estudo de Sztutman e Rodrigues (2002) em Floresta Ombrófila Densa de Terras Baixas da planície litorânea de São Paulo. Esta espécie por ser umbrófila, tende a se tornar mais abundante sob condições de floresta mais desenvolvida (KLEIN, 1974). Neste estudo sua maior densidade foi para menor classe de altura, indicativo de um possível sucesso de estabelecimento da espécie na área (HARPER, 1977). 
Tabela 3. Variáveis fitossociológicas em ordem decrescente de valor de importância para as 20 principais espécies registradas no levantamento estrutural do Compartimento Mal Drenado de Floresta Ombrófila Densa Aluvial, na Reserva Natural Serra do Itaqui, Guaraqueçaba, PR.

Table 3. Phytosociological parameters for the top 20 tree species, arranged in decreasing order of importance value, obtained at a poorly drained site in the Dense Alluvial Ombrophilous Forest of the Natural Reserve of Sierra Itaqui, Guaraqueçaba, State of Paraná.

\begin{tabular}{|c|c|c|c|c|c|c|c|c|c|}
\hline Espécie & $\mathbf{n}$ & $\begin{array}{c}\text { DA } \\
(\mathbf{n} / \mathbf{h a})\end{array}$ & $\begin{array}{l}\text { DR } \\
(\%)\end{array}$ & $\begin{array}{l}\text { FA } \\
(\%)\end{array}$ & FR & $\begin{array}{c}\text { DoA } \\
\left(\mathrm{m}^{2} / \mathrm{ha}\right)\end{array}$ & $\begin{array}{c}\text { DoR } \\
(\%)\end{array}$ & VI & VC \\
\hline Pera glabrata & 50 & 312,5 & 12,66 & 100,0 & 7,88 & 6,47 & 19,09 & 39,63 & 31,75 \\
\hline Psychotria nuda & 97 & 606,2 & 24,56 & 93,7 & 7,39 & 1,85 & 5,47 & 37,41 & 30,02 \\
\hline Psidium cattleianum & 23 & 143,7 & 5,82 & 62,5 & 4,93 & 2,17 & 60,40 & 17,15 & 12,23 \\
\hline Eugenia cf. blastantha & 24 & 150,0 & 6,08 & 50,0 & 3,94 & 1,14 & 3,37 & 13,38 & 9,44 \\
\hline Tapirira guianensis & 4 & 25,0 & 1,01 & 18,7 & 1,48 & 3,23 & 9,55 & 12,04 & 10,56 \\
\hline $\begin{array}{l}\text { Syagrus } \\
\text { romanzoffiana }\end{array}$ & 9 & 56,2 & 2,28 & 50,0 & 3,94 & 1,62 & 4,78 & 10,99 & 7,05 \\
\hline Andira anthelminthica & 10 & 62,5 & 2,53 & 50,0 & 3,94 & 1,46 & 4,31 & 10,78 & 6,84 \\
\hline Euterpe edulis & 16 & 100,0 & 4,05 & 56,2 & 4,43 & 0,60 & 1,78 & 10,26 & 5,83 \\
\hline $\begin{array}{l}\text { Calophyllum } \\
\text { brasiliense }\end{array}$ & 4 & 25,0 & 1,01 & 25,0 & 1,97 & 2,13 & 6,29 & 9,27 & 7,30 \\
\hline Myrcia insularis & 10 & 62,5 & 2,53 & 43,7 & 3,45 & 0,86 & 2,53 & 8,51 & 5,06 \\
\hline Myrca glabra & 8 & 50,0 & 2,03 & 43,7 & 3,45 & 0,91 & 2,69 & 8,16 & 4,71 \\
\hline Posoqueria latifolia & 7 & 43,7 & 1,77 & 43,7 & 3,45 & 0,74 & 2,19 & 7,41 & 3,96 \\
\hline Guarea macrophylla & 10 & 62,5 & 2,53 & 43,7 & 3,45 & 0,37 & 1,09 & 7,07 & 3,63 \\
\hline Amaioua guianensis & 9 & 56,2 & 2,28 & 37,5 & 2,96 & 0,37 & 1,08 & 6,32 & 3,36 \\
\hline Ilex theezans & 6 & 37,5 & 1,52 & 31,2 & 2,46 & 0,61 & 1,81 & 5,79 & 3,32 \\
\hline $\begin{array}{l}\text { Hyeronima } \\
\text { alchorneoides }\end{array}$ & 6 & 37,5 & 1,52 & 31,2 & 2,46 & 0,52 & 1,55 & 5,53 & 3,06 \\
\hline Maytenus robusta & 8 & 50,0 & 2,03 & 25,0 & 1,97 & 0,25 & 0,73 & 4,73 & 2,76 \\
\hline Vochysia bifalcata & 5 & 31,2 & 1,27 & 12,5 & 0,99 & 0,73 & 2,14 & 4,39 & 3,41 \\
\hline Jacaranda puberula & 6 & 37,5 & 1,52 & 18,7 & 1,48 & 0,41 & 1,21 & 4,20 & 2,73 \\
\hline Cabralea canjerana & 3 & 18,7 & 0,76 & 12,5 & 0,99 & 0,59 & 1,74 & 3,48 & 2,50 \\
\hline
\end{tabular}

n: número de indivíduos; DA: densidade absoluta; DR: densidade relativa; FA: frequência absoluta; FR: frequência relativa; DoA: dominância absoluta; DoR: dominância relativa; VI: valor de importância; VC: valor de cobertura.

O diâmetro médio dos fustes dos indivíduos vivos amostrados foi de $11,1 \mathrm{~cm}$. O diâmetro máximo encontrado foi de Tapirira guianensis com 69,7 cm, seguida de Calophyllum brasiliense com 45,2 cm, Andira anthelmia com $31,5 \mathrm{~cm}$, e de Pera glabrata com $31,2 \mathrm{~cm}$. Os demais indivíduos apresentaram diâmetro igual ou inferior a $29,6 \mathrm{~cm}$. A área basal calcula para o compartimento mal drenado foi de $33,87 \mathrm{~m}^{2} / \mathrm{ha}$.

A comunidade é composta por três estratos arbóreos, sendo a altura média equivalente a 10,4 $\mathrm{m}$. $\mathrm{O}$ estrato inferior foi definido entre 2 e $10 \mathrm{~m}$ e apresentou 58,5\% do total de indivíduos amostrados na área. Psychotria nuda é a espécie mais representativa deste estrato com 97 indivíduos menores que $7 \mathrm{~m}$ de altura, todavia, é considerada típica, tanto do sub-bosque da Floresta Ombrófila Densa Submontana, quanto das áreas úmidas da planície (VELOSO; KLEIN, 1968; BORGO, 2004).

No estrato intermediário, entre 10,1 e $17,0 \mathrm{~m}$ de altura, estão presentes $23 \%$ do total de indivíduos, com vários representantes de Pera glabrata, Psidium cattleianum, Eugenia cf. blastantha e Syagrus romanzoffiana. Com exceção desta última, as demais espécies apareceram em todos os estratos. Por fim, o estrato superior, entre 17,1 e 23,0 m, é composto por uma densidade menor de indivíduos (15,6\% do total), quando comparado aos demais estratos. Pera glabrata é a espécie mais abundante, a qual divide espaço com outras sete espécies da família Myrtaceae.

Alguns indivíduos (2,8\% do total) emergem do dossel com alturas variando de 24 a $26 \mathrm{~m} \mathrm{e}$ pertencem às espécies de Myrcia glabra, Vochysia bifalcata, Pera glabrata, Calophyllum brasiliense, Tapirira guianensis, Cabralea canjerana e Myrcia dichrophylla.

A densidade relativamente baixa calculada para o estrato superior configura uma fisionomia de dossel aberto que permite a entrada de luz no interior da floresta. Este estrato ainda não está bem consolidado provavelmente devido à limitação imposta pelo substrato. Esta condição ecológica favorece o 
desenvolvimento de espécies heliófitas, como Pera glabrata e Psidium cattleianum, presentes nos três estratos.

Vegetação do compartimento muito mal drenado

Ao todo foram registrados 396 indivíduos (2.475 indivíduos/ha), pertencentes a 23 famílias, 37 gêneros e 48 espécies, sendo 24 comuns ao compartimento mal drenado. A família de maior riqueza foi Myrtaceae, com um total de oito espécies. As variáveis fitossociológicas calculadas para as 20 principais espécies encontram-se na tabela 4.

Tabela 4. Variáveis fitossociológicas em ordem decrescente de valor de importância para as 20 principais espécies registradas no levantamento estrutural do Compartimento Muito Mal Drenado de Floresta Ombrófila Densa Aluvial, na Reserva Natural Serra do Itaqui, Guaraqueçaba, PR.

Table 4. Phytosociological parameters for the top 20 tree species, arranged in decreasing order of importance value, obtained at a very poorly drained site in the Dense Alluvial Ombrophilous Forest of the Natural Reserve of Sierra Itaqui, Guaraqueçaba, State of Paraná.

\begin{tabular}{|c|c|c|c|c|c|c|c|c|c|}
\hline Espécie & $\mathbf{n}$ & $\begin{array}{c}\text { DA } \\
(\mathbf{n} / \mathbf{h a})\end{array}$ & $\begin{array}{l}\text { DR } \\
(\%)\end{array}$ & $\begin{array}{l}\text { FA } \\
(\%)\end{array}$ & $\begin{array}{l}\text { FR } \\
(\%)\end{array}$ & $\begin{array}{c}\text { DoA } \\
\left(\mathrm{m}^{2} / \mathrm{ha}\right)\end{array}$ & $\begin{array}{c}\text { DoR } \\
(\%)\end{array}$ & VI & VC \\
\hline Tabebuia cassinoides & 112 & 700,0 & 28,28 & 75,0 & 6,42 & 7,87 & 23,10 & 57,80 & 51,38 \\
\hline Psidium cattleianum & 52 & 325,0 & 13,13 & 93,7 & 8,02 & 7,28 & 21,36 & 42,51 & 34,49 \\
\hline $\begin{array}{l}\text { Syagrus } \\
\text { romanzoffiana }\end{array}$ & 35 & 218,7 & 8,84 & 93,7 & 8,02 & 4,76 & 13,97 & 30,83 & 22,81 \\
\hline $\begin{array}{l}\text { Tibouchina } \\
\text { trichopoda }\end{array}$ & 34 & 212,5 & 8,59 & 81,2 & 6,95 & 1,14 & 3,34 & 18,88 & 11,93 \\
\hline Tabebuia umbellata & 12 & 75,0 & 3,03 & 56,2 & 4,81 & 1,77 & 5,20 & 13,04 & 8,23 \\
\hline $\begin{array}{l}\text { Calophyllum } \\
\text { brasiliense }\end{array}$ & 4 & 25,0 & 1,01 & 18,7 & 1,60 & 2,97 & 8,72 & 11,33 & 9,73 \\
\hline Ocotea pulchella & 9 & 56,2 & 2,27 & 43,7 & 3,74 & 1,19 & 3,48 & 9,50 & 5,76 \\
\hline Andira anthelminthica & 6 & 37,5 & 1,52 & 37,5 & 3,21 & 0,86 & 2,52 & 7,25 & 4,04 \\
\hline Ilex pseudobuxus & 10 & 62,5 & 2,53 & 37,5 & 3,21 & 0,27 & 0,80 & 6,53 & 3,32 \\
\hline Clusia criuva & 5 & 31,2 & 1,26 & 31,2 & 2,67 & 0,78 & 2,28 & 6,22 & 3,54 \\
\hline Inga edulis & 8 & 50,0 & 2,02 & 31,2 & 2,67 & 0,36 & 1,07 & 5,76 & 3,09 \\
\hline Guarea macrophylla & 7 & 43,7 & 1,77 & 37,5 & 3,21 & 0,18 & 0,53 & 5,51 & 2,30 \\
\hline Ilex dumosa & 5 & 31,2 & 1,26 & 31,2 & 2,67 & 0,17 & 0,50 & 4,44 & 1,76 \\
\hline Tibouchina pulchra & 5 & 31,2 & 1,26 & 31,2 & 2,67 & 0,13 & 0,39 & 4,32 & 1,65 \\
\hline Euterpe edulis & 7 & 43,7 & 1,77 & 18,7 & 1,60 & 0,24 & 0,71 & 4,09 & 2,48 \\
\hline Pera glabrata & 5 & 31,2 & 1,26 & 25,0 & 2,14 & 0,10 & 0,29 & 3,69 & 1,56 \\
\hline Myrsine gardneriana & 5 & 31,2 & 1,26 & 18,7 & 1,60 & 0,24 & 0,71 & 3,58 & 1,98 \\
\hline Inga sessilis & 4 & 25,0 & 1,01 & 25,0 & 2,14 & 0,10 & 0,29 & 3,44 & 1,30 \\
\hline $\begin{array}{l}\text { Vernonanthura } \\
\text { puberula }\end{array}$ & 4 & 25,0 & 1,01 & 25,0 & 2,14 & 0,06 & 0,16 & 3,31 & 1,17 \\
\hline $\begin{array}{l}\text { Ternstroemia } \\
\text { brasiliensis }\end{array}$ & 3 & 18,7 & 0,76 & 12,5 & 1,07 & 0,37 & 1,08 & 2,91 & 1,84 \\
\hline
\end{tabular}

n: número de indivíduos; DA: densidade absoluta; DR: densidade relativa; FA: frequência absoluta; FR: frequência relativa; DoA: dominância absoluta; DoR: dominância relativa; VI: valor de importância; VC: valor de cobertura.

Tabebuia cassinoides e Psidium cattleianum possuem os maiores valores de importância, correspondendo juntas a 33,4\% do valor total obtido para todas as espécies amostradas. Tabebuia cassinoides (caxeta) possui elevada densidade representada por $28,2 \%$ do total de indivíduos vivos amostrados, alta frequência (75\%) e indivíduos de grande porte, apresentando não somente o maior valor de importância, como também o maior valor de cobertura.

A densidade de Psidium cattleianum foi inferior a de Tabebuia cassinoides em mais de 50\%, no entanto, sua frequência atingiu $93 \%$. Cerca de 50\% de seus indivíduos apresentaram tronco perfilhado e grande porte. Assim, como neste trabalho, no estudo fitossociológico realizado em um caxetal do município de Guaratuba, PR, P. cattleianum ocupou a segunda posição em valor de importância (ZILLER, 1992). 
Com apenas quatro representantes, Calophyllum brasiliense manteve-se entre as 10 espécies de maior importância. Isto significa que a baixa densidade e frequência foram compensadas pelo porte de seus indivíduos (diâmetro mínimo $=6,7 \mathrm{~cm}$; diâmetro máximo $=54,4 \mathrm{~cm}$ e diâmetro médio $=33,3 \mathrm{~cm}$ ).

Tabebuia umbellata é uma espécie higrófita conhecida popularmente como ipê-do-brejo ou ipêda-várzea (LORENZI, 2002). É característica da floresta primária das planícies aluviais e está frequentemente associada à Tabebuia cassinoides e Syagrus romanzoffiana (KLEIN, 1984; BORGO, 2004), conforme observado neste estudo e em levantamentos realizados por Ziller (1992).

Ocotea pulchella é descrita como pioneira das planícies quaternárias, planta semidecídua, heliófita e seletiva higrófita, comum na Floresta Ombrófila Mista, mas pode ser frequente em algumas localidades da restinga litorânea e do cerrado de São Paulo (LORENZI, 2002).

O diâmetro médio dos fustes dos indivíduos vivos amostrados no compartimento muito mal drenado foi de $11,3 \mathrm{~cm}$. Os diâmetros máximos, equivalentes a 54,4 e $51,2 \mathrm{~cm}$ foram para Calophyllum brasiliense, seguidos de um representante de Tabebuia umbellata com 41,7 cm, Tabebuia cassinoides com $38 \mathrm{~cm}$, Syagrus romanzoffiana com 33,1 cm, Psidium cattleianum com $32 \mathrm{~cm}$ e Tabebuia cassinoides com 30,3 cm. Os demais 376 indivíduos apresentaram diâmetro igual ou inferior a $29,2 \mathrm{~cm}$, sendo que cerca de $80 \%$ das árvores possuem diâmetro inferior a $15,3 \mathrm{~cm}$. A área basal calculada para $\mathrm{o}$ compartimento muito mal drenado foi de $34,0 \mathrm{~m}^{2} / \mathrm{ha}$.

Nesta comunidade foram observados somente dois estratos arbóreos e calculada uma altura média de 8,3 m. O estrato inferior, entre 1 e $9 \mathrm{~m}$, manteve $64 \%$ do total de indivíduos vivos amostrados e é dominado por Tabebuia cassinoides (62 representantes). Em seguida tem-se Tibouchina trichopoda, que é típica do sub-bosque (BORGO, 2004) e foi representada por 34 indivíduos.

O estrato superior, entre 9,1 e 14,0 m de altura, foi composto por 116 indivíduos ( $30 \%$ do total) e manteve Tabebuia cassinoides como espécie dominante (cerca de $32 \%$ do total de indivíduos). Com densidade reduzida (5,5\% do total amostrado), alguns indivíduos atingiram entre 14,1 e 20,0 m de altura, destacando-se Tabebuia cassinoides, que apareceu juntamente com poucos representantes de outras seis espécies: Syagrus romanzoffiana, Jacaranda puberula, Psidium cattleianum, Calophyllum brasiliense, Tabebuia umbellata e Ocotea pulchella. Dois indivíduos de Calophyllum brasiliense superaram fortemente o padrão de altura dos indivíduos amostrados, chegando a $25 \mathrm{~m}$.

Tabebuia cassinoides é uma espécie altamente seletiva em termos de ocupação, com ocorrência restrita aos solos saturados por água durante a maior parte do ano e com altos teores de matéria orgânica (Organossolos) e, eventualmente, presente em Espodossolos hidromórficos com horizonte hístico. No Paraná, a ocorrência de Tabebuia cassinoides está limitada à região do Vale do Ribeira e da planície litorânea (RACHWAL; CURCIO, 2001). Associações arbóreas de baixa diversidade, em que há o predomínio desta espécie e ausência de estratificação vertical são denominadas caxetais (GALVÃO et al., 2002; BORGO, 2004).

Os resultados obtidos para esta comunidade divergem das características ambientais descritas em outros estudos, em especial quanto ao tipo de substrato que a caxeta está associada. Na planície litorânea paranaense a ocorrência da caxeta tem sido descrita principalmente sobre solos orgânicos com diferentes texturas de substrato, variando de acordo com sua gênese (ZILLER, 1992; RODERJAN et al., 1996).

Estudo realizado em três superfícies de agradação do rio Guaraguaçu/PR mostrou alto valor de importância para Tabebuia cassinoides (SVOLENSKI, 2000). O solo descrito para estas áreas foi uma associação entre Neossolo Flúvico com horizonte A variando entre moderado, húmico e hístico e Organossolo Háplico. Em todas as categorias foi constatada alta saturação hídrica ao longo de todo ano. A presença da caxeta não foi exclusiva em substrato orgânico, mas suas maiores densidades foram para as parcelas em Organossolo.

No presente estudo, a caxeta ocorre em alta densidade sobre o substrato mineral periodicamente alagado. É importante ressaltar sobre a dinâmica constatada na área, onde durante o verão a saturação hídrica local com afloramento de lençol freático provavelmente determina condições ambientais similares aos ambientes de solos orgânicos. Este fato pode auxiliar na justificativa da expressiva presença da caxeta em solo mineral, onde sazonalmente a anoxia local pode favorecer o acúmulo de matéria orgânica em níveis suficientes para o desenvolvimento desta espécie. Por outro lado, em épocas de menor pluviosidade a área sofre um processo de subsidência, em função da redução do nível do lençol freático e decomposição da matéria orgânica. Fenômeno semelhante foi descrito para solos orgânicos por Rachwal e Curcio (2001). Sendo assim, a elevação periódica do lençol freático e o tempo de permanência deste 
evento possivelmente possam ser considerados fatores ambientais mais determinantes para ocorrência de Tabebuia cassinoides, do que o substrato orgânico.

Os resultados obtidos neste compartimento foram comparados com uma compilação de dados realizada por Galvão et al. (2002) sobre outras investigações em áreas de ocorrência da caxeta no estado do Paraná (ZILLER,1992; RODERJAN et al.,1996). Nesta compilação de dados, Galvão et al. (2002) estabeleceram uma classificação das fisionomias das comunidades vegetais conforme seu grau de desenvolvimento, baseado em seus parâmetros florísticos e estruturais (Tabela 5).

Tabela 5. Comparação dos parâmetros fitossociológicos de diferentes comunidades vegetais da planície litorânea paranaense com os dados obtidos para a comunidade situada no Compartimento muito mal drenado deste estudo, com critério de inclusão modificado para DAP $\geq 10 \mathrm{~cm}$.

Table 5. Comparison of phytosociological parameters from different plant communities in the coastal plain of Paraná with data obtained from the very poorly drained site, with inclusion criteria modified for $\mathrm{DBH} \geq 10 \mathrm{~cm}$.

\begin{tabular}{|c|c|c|c|c|c|c|c|c|}
\hline $\begin{array}{l}\text { Comunidades } \\
\text { vegetais }\end{array}$ & PST* & BAT* & CAB* & ATA* & GT1** & ALE* & GT2** & $\begin{array}{c}\text { Este } \\
\text { estudo }\end{array}$ \\
\hline DA/ha & 1610 & 1951 & 1384 & 2050 & 1333 & 1685 & 1085 & 1125 \\
\hline DoA/ha & 31 & 36 & 49 & 39 & 28 & 50 & 40 & 29 \\
\hline $\mathrm{N}^{\circ}$ de estratos & 1 & 1 & 2 & 3 & 3 & 3 & 3 & 2 \\
\hline $\mathrm{N}^{\circ}$ de spp. & 13 & 13 & 27 & 29 & 26 & 36 & 78 & 25 \\
\hline DR caxeta & 85 & 68 & 61 & 53 & 55 & 48 & 9 & 30 \\
\hline DR guanandi & 0 & 0 & 2 & 4 & 2 & 9 & 9 & 2 \\
\hline $\begin{array}{l}\text { Fitofisionomia } \\
\text { geral }\end{array}$ & pioneira & pioneira & transicional & transicional & transicional & FODTB & FODTB & transicional \\
\hline
\end{tabular}

Neste estudo, Tabebuia cassinoides destacou-se como a espécie mais abundante em todos os estratos. Isto significa que, além de existirem indivíduos iniciando a ocupação de um terceiro estrato, novos indivíduos continuam sendo acrescidos à comunidade. Todavia, a sua densidade relativa é inferior a das comunidades apresentadas na tabela 5, exceto se comparada ao caxetal Guaratuba 2.

Quanto à densidade relativa de Calophyllum brasiliense (guanandi), o valor pouco expressivo descrito neste estudo assemelha-se aos valores encontrados para as florestas consideradas em fase de transição. O mesmo verificou-se para o reduzido valor de riqueza de espécies.

Ainda observando-se a tabela 5, dominância e densidade absolutas foram parâmetros muito variáveis entre as comunidades. Nota-se que não há um padrão de maior ou menor valor em função do grau de desenvolvimento estabelecido para as comunidades. Portanto, para determinar o estádio de desenvolvimento de uma comunidade vegetal, é importante considerar um conjunto de parâmetros florísticos e estruturais, pois a análise de uma ou poucas variáveis pode ser insuficiente para uma classificação segura.

De acordo com os parâmetros e análises feitas por Galvão et al. (2002), pode considerar-se que a comunidade deste estudo encontra-se em fase de transição entre a formação pioneira e a de Floresta Ombrófila Densa Aluvial. Considera-se ainda, que o padrão de altura registrado para os indivíduos arbóreos reforça a ideia de que se trata de uma floresta em transição, dado que os caxetais, fase arbórea inicial típica destes ambientes, apresentam alturas máximas entre 8 e $12 \mathrm{~m}$, com eventuais emergentes que não ultrapassam 16 metros (RODERJAN et al., 1996).

\section{Compartimento mal drenado e compartimento muito mal drenado}

Apesar da maior hidromorfia constatada no ambiente muito mal drenado, as duas áreas se mostraram estruturalmente muito semelhantes, exceto com relação à altura média, que indicou a presença de árvores mais altas e um estrato superior mais denso no ambiente mal drenado, quando comparado ao muito mal drenado (Tabela 6). 
Tabela 6. Teste $t$ de Student para as variáveis fitossociológicas gerais calculadas para cada compartimento de Floresta Ombrófila Densa Aluvial estudado na Reserva Natural Serra do Itaqui, Guaraqueçaba, PR.

Table 6. Student $t$ Test of the phytosociological parameters calculated for each site in the Dense Alluvial Ombrophilous Forest in the Natural Reserve of Sierra Itaqui, Guaraqueçaba, State of Paraná.

\begin{tabular}{lccc}
\hline Parâmetros & $\boldsymbol{t}$ & $\mathbf{X}_{\text {CMD }} \pm \mathbf{I C}$ & $\mathbf{X}_{\text {CMMD }} \pm \mathbf{I C}$ \\
\hline Área basal $\left(\mathrm{m}^{2} / \mathrm{ha}\right)$ & 0,44 & $33,87 \pm 6,88$ & $34,09 \pm 7,66$ \\
Diâmetro médio & 1,36 & $11,11 \pm 0,78$ & $11,32 \pm 1,04$ \\
Altura média & $5,07 *$ & $10,41 \pm 0,86$ & $8,35 \pm 0,70$ \\
\hline$\left.{ }^{*} \alpha=0,01 ; t=2,75\right) ;$ CMD: compartimento mal drenado; CMMD: compartimento muito mal drenado; IC: intervalo de \\
confiança.
\end{tabular}

Para o componente amostral relativo aos indivíduos vivos o valor do índice de diversidade de Shannon (H') foi de 3,13 e o de Simpson (1-D) igual a 0,91 no compartimento mal drenado. Para o compartimento muito mal drenado, os índices foram $\mathrm{H}^{\prime}=2,86$ e $1-D=0,88$. Quanto ao índice de eqüidade (J'), os valores foram de 0,77 e 0,73 , respectivamente.

A menor diversidade em ambiente muito mal drenado também é acompanhada de menor riqueza. O número de espécies é cerca de $15 \%$ menor que a verificada no compartimento mal drenado. Índices mais baixos são comumente descritos em áreas de substrato encharcado das Florestas Tropicais quando comparados a áreas de melhor drenagem (IVANAUSKAS et al., 1997; SZTUTMAN; RODRIGUES, 2002), em razão de poucas espécies terem desenvolvido adaptações que possibilitem sua sobrevivência em ambientes alagados (JOLY, 1991).

Os valores determinados para diversidade encontram-se dentro da faixa esperada para planícies litorâneas, a qual é muito variável em função da alta heterogeneidade ambiental destas regiões (SZTUTMAN; RODRIGUES, 2002), que ora disponibiliza um ambiente favorável ao desenvolvimento de grande diversidade florística, ora restringe o estabelecimento de muitas espécies. A alta densidade de caxeta onde ocorrem alagamentos periódicos indica sua dominância ecológica na área. Em florestas tropicais é comum que a dominância ecológica seja mais pronunciada sob condições ambientais extremas (DALY; MITCHELL, 2000).

O valor de 29,63\% obtido para o índice de semelhança florística de Jaccard indica baixa similaridade entre os dois compartimentos. De acordo com Kent e Coker (1992) duas áreas são semelhantes quando este valor é igual ou superior $50 \%$.

Enquanto no ambiente muito mal drenado Tabebuia cassinoides ocupou a primeira posição, no compartimento mal drenado não apresentou nenhum indivíduo. Neste ambiente, Pera glabrata foi a espécie de maior VI e, apesar de ocorrer em solo muito mal drenado, sua densidade está muito reduzida. Considerando somente as 10 espécies de maior VI em cada comunidade, nota-se que apenas quatro são comuns às duas áreas, sendo estas: Psidium cattleianum, Syagrus romanzoffiana, Andira anthelmia e Calophyllum brasiliense.

Psidium cattleianum e Syagrus romanzoffiana apresentam densidade, frequiência e dominância maiores na área sujeita a alagamento periódico, todavia, são espécies seletivas higrófitas (LORENZI, 2002). Como caracterizam-se também por serem heliófitas (TONIATO et al., 1998; LORENZI, 2002), não se pode descartar a hipótese de que a menor disponibilidade de luz no interior da floresta mais bem drenada esteja influenciando na estrutura populacional destas espécies.

Andira anthelmia é uma espécie seletiva higrófita de distribuição ampla, mas geralmente com baixa densidade populacional (LORENZI, 2002). Neste estudo, as diferenças de características físicas e biológicas entre as áreas parecem ser indiferentes ao estabelecimento desta espécie.

Calophyllum brasiliense está presente nas duas comunidades com mesma densidade, mas seus indivíduos apresentaram maior porte em solo muito mal drenado. É uma espécie de comum ocorrência em um largo gradiente de umidade, muitas vezes apresentando vantagem seletiva sobre outros taxa em solo permanentemente encharcado (MARQUES; JOLY, 2000).

Tabebuia umbellata, com presença de apenas dois indivíduos em compartimento mal drenado, destaca-se no ambiente periodicamente alagado por ser outra arbórea bem adaptada às condições de elevada saturação hídrica (RODERJAN et al., 1996; LORENZI, 2002). 
O número reduzido de espécies presentes no compartimento muito mal drenado está possivelmente associado à combinação entre restrição ambiental imposta pela saturação hídrica do solo (LOBO; JOLY, 2000; SILVA et al., 2007) e a tolerância ecológica das espécies (RICKLEFS, 2003). Planícies de inundação que sofrem condições extremas de deficiência em drenagem tendem a suportar florestas menos diversas, pois poucas espécies são tolerantes ao alagamento (JOLY, 1991; DALY; MITCHELL, 2000).

As comparações florísticas entre remanescentes de formações florestais ciliares têm mostrado que essas áreas são muito diversas, com valores de similaridade muito baixos, mesmo entre áreas de grande proximidade espacial (RODRIGUES; NAVE, 2000). A intensidade dessas diferenças é determinada pelas características do ambiente, dentre as quais o nível do lençol freático tem sido colocado em destaque (SCARANO et al., 1997). São vários os estudos que mostram diferenças florísticas ao longo de um gradiente topográfico e de umidade (JOLY, 1991; IVANAUSKAS et al., 1997; TONIATO et al.,1998; SVOLENSKI, 2000; SZTUTMAN; RODRIGUES, 2002; CARVALHO et al., 2005; SILVA et al., 2007 e VAN DEN BERG et al., 2007).

\section{CONCLUSÕES}

- Com base nos resultados obtidos, verificou-se que a mesma unidade fitogeográfica pode conter tipos florestais contíguos e distintos entre si, do ponto de vista florístico e estrutural em resposta a variações ambientais às vezes muito sutis. Isto reforça a idéia, mesmo em escala reduzida, do grande mosaico vegetacional presente na planície litorânea brasileira e a necessidade de estudos e ações conservacionistas que considerem a heterogeneidade ambiental. Os trabalhos de recuperação de ambientes aluviais degradados não podem ignorar a complexidade dessas áreas. A escolha das espécies, além da diversidade, deve considerar outros parâmetros ecológicos como adaptação às condições físicas do meio, seus padrões de abundância na comunidade e características sucessionais.

- Em razão da proximidade geográfica, das similaridades climáticas e edáficas existentes entre as comunidades estudadas, o principal fator determinante de suas estruturas e composição florística parece estar intimamente relacionado à condição de drenagem do solo, associada diretamente com a topografia da região.

\section{AGRADECIMENTOS}

Este trabalho representa parte da dissertação de Mestrado da primeira autora, Programa de PósGraduação em Ecologia e Conservação da Universidade Federal do Paraná. Agradecemos à SPVS pelo apoio logístico e por toda infra-estrutura cedida durante a realização dos estudos em campo, à Fundação O Boticário pelo apoio financeiro, ao Professor Doutor Carlos Veloso Roderjan (Depto. de Ciências Florestais - UFPR) pelas valiosas sugestões, à pesquisadora Marilia Borgo (SPVS) pelo grande auxílio na identificação do material botânico e ao pesquisador Gustavo Ribas Curcio (EMBRAPA Florestas) pelas ricas observações e contribuições que possibilitaram uma adequada interpretação das características dos substratos das áreas.

\section{REFERÊNCIAS}

ARAUJO, M. M.; LONGHI S. L.; BRENA D. A.; BARROS P. L. C.; FRANCO S. Análise de agrupamento da vegetação de um fragmento de Floresta Estacional Decidual Aluvial, Cachoeira do Sul, RS, Brasil. Ciência Florestal, Santa Maria, v. 14, n. 1, p. 133 - 147, 2004.

BARDDAL, M. L.; RODERJAN, C. V.; GALVÃO, F.; CURCIO, G. R. Caracterização florística e fitossociológica de um trecho sazonalmente inundável de floresta aluvial, em Araucária, PR. Ciência Florestal, Santa Maria, v. 14, n. 2, p. 37 - 50, 2004.

BIANCHINI, E.; POPOLO, R. S.; DIAS, M. C.; PIMENTA, J. A. Diversidade e estrutura de espécies arbóreas em área alagável do município de Londrina, Sul do Brasil. Acta Botanica Brasilica, São Paulo, v. 17, p. 405 - 419, 2003.

BORGO, M. Diagnóstico da Vegetação das Reservas Naturais Serra do Itaqui e Rio Cachoeira. Curitiba: Sociedade de Pesquisa em Vida Selvagem e Educação Ambiental, 2004. Relatório Técnico. 
CARVALHO, D. A.; OLIVEIRA-FILHO, A. T.; VILELA, E. A.; CURI, N.; VAN DEN BERG, E.; FONTES, M. A. L.; BOTEZELLI, L. Distribuição de espécies arbóreo-arbustivas ao longo de um gradiente de solos e topografia em um trecho de floresta ripária do rio São Francisco em Três Marias, MG, Brasil. Revista Brasileira de Botânica, São Paulo, v. 28, n. 2, p. 329 - 345, 2005.

CARVALHO, F. A.; NASCIMENTO, M. T.; OLIVEIRA-FILHO, A. T. Composição, riqueza e heterogeneidade da flora arbórea da bacia do rio São João, RJ, Brasil. Acta Botanica Brasilica, São Paulo, v. 22, n. 4, p. 929 - 940, 2008.

CURCIO, G. R.; BONNET, A.; PESTANA, D.; SOUZA, L.; SOCHER, L. G.; GALVÃO, F.; RODERJAN, C. V. Compartimentação toposseqüencial e caracterização fitossociológica de um capão de Floresta Ombrófila Mista. Floresta, v. 36, n. 3, p. 1 - 9, 2006.

DALY, D. C.; MITCHELL, J. D. Lowland vegetation of tropical South America - an overview. In: LENTZ, D. Imperfect balance: Landscape transformations in the pre-Columbian Americas. New York: Columbia University Press, 2000. p. 391 - 454.

EMPRESA BRASILEIRA DE PESQUISA AGROPECUÁRIA (EMBRAPA). Manual de Métodos de Análise de Solos. 2 ed. Rio de Janeiro: Centro Nacional de Pesquisa de Solos, 1997.

FERNANDES, C. R. Floresta Atlântica: Reserva da Biosfera. 20 ed. Curitiba: Tempo Integral, 2003.

FRANKE, C. R.; ROCHA, P. L. B.; KLEIN, W.; GOMES, S. L. Mata Atlântica e Biodiversidade. Salvador: Editora da Universidade Federal da Bahia, 2005.

GALVÃO, F.; RODERJAN, C. V.; KUNIYOSHI, Y. S.; ZILLER, S. R. Composição florística e fitossociologia de caxetais do Estado do Paraná - Brasil. Revista Floresta, Curitiba, v. 32, n. 1, p. 17 - 39, 2002.

HARPER, J. L. Population Biology of Plants. Acad. Pess. London, 1977.

INSTITUTO AGRONÔMICO DO PARANÁ (IAPAR). Resumos Históricos Climáticos - Sistema de Monitoramento Agroclimático do Paraná. Disponível em: <http://www.iapar.br/modules/conteudo/ conteudo.php?conteudo=322 >. Acesso em: 15/08/2012.

IVANAUSKAS, N. M.; RODRIGUES, R. R.; NAVE, A. G. Aspectos ecológicos de um trecho de floresta de brejo em Itatinga, SP: florística, fitossociologia e seletividade de espécies. Revista Brasileira de Botânica, São Paulo, v. 20, n. 2, p. 139 - 153, 1997.

JOLY, C. A. Flooding Tolerance in tropical trees. In: JACKSONS, M. B.; DAVIS, D. D.; LAMBERS, H. Plant life under oxygen deprivation. SPB Academic Publishing, The Hague, 1991. p. 23 - 43.

KENT, M.; COKER, P. Vegetation Description and Analysis. London: Belhaven Press, 1992.

KLEIN, R. M. Euterpe edulis Martius - observações ecológicas. In: REITZ, R. (Ed.). Flora Ilustrada Catarinense. Itajaí, Herbário Barbosa Rodrigues: Editora da Universidade Federal de Santa Catarina, 1974. p. $102-105$.

Mapa fitogeográfico do Estado de Santa Catarina. Flora Ilustrada Catarinense. Itajaí: Herbário Barbosa Rodrigues: Editora da Universidade Federal de Santa Catarina, 1978.

Aspectos dinâmicos da vegetação do sul do Brasil. Sellowia, Itajaí: Anais Botânicos do Herbário Barbosa Rodrigues, n. 36, p. 5 - 54, 1984.

LOBO, P. C.; JOLY, C. A. Aspectos ecofisiológicos da vegetação de mata ciliar do sudeste do Brasil. In: RODRIGUES, R. R.; LEITÃO-FILHO, H. F. Matas Ciliares: conservação e recuperação. São Paulo: Editora da Universidade de São Paulo, 2000. p. 143 - 157.

LORENZI, H. Árvores Brasileiras - manual de identificação e cultivo de plantas arbóreas nativas do Brasil. 4 ed. São Paulo: Instituto Plantarum: Nova Odessa, 2002. v. 1.

MAACK, R. Geografia física do estado do Paraná. 2 ed. Rio de Janeiro: Ed. J. Olimpio, 1981. 
MARQUES, M. C. M.; JOLY, C. A. Estrutura e dinâmica de uma população de Calophyllum brasiliense Camb. Em floresta higrófila do sudeste do Brasil. Revista Brasileira de Botânica, São Paulo, v. 23, n. 1, p. $107-112,2000$.

MARQUES, M. C. M.; SILVA, S. M.; SALINO, A. Florística e estrutura do componente arbustivoarbóreo de uma floresta higrófila da bacia do rio Jacaré-Pepira, SP, Brasil. Acta Botanica Brasilica, São Paulo, v. 17, p. 495 - 506, 2003.

MULLER-DOMBOIS, D.; ELLENBERG, H. Aims and methods of vegetation ecology. New York: John Wiley \& Sons, 1974.

MUNSELL SOIL COLOR COMPANY. Munsell soil color charts. Baltimore, 1975. v. 1.

OLIVEIRA-FILHO, A. T.; FONTES, M. A. L. Patterns of floristic Differentiation among Atlantic forests in southeastern Brazil and the influence of climate. Biotropica, v. 32, n. 4b, p. 783 - 810, 2000.

PIELOU, E. C. Ecological diversity. New York: John Wilwy \& Sons, 1975.

RACHWAL, M. F. G.; CURCIO, G. R. Atributos pedológicos e ocorrência de caixeta no litoral paranaense, Brasil. Scientia Forestalis, v. 59, p. 153 - 163, 2001.

RICKLEFS, R. A Economia da Natureza. 5 ed. Rio de Janeiro: Guanabara Koogan, 2003.

ROCHA, A. L.; ZITTA, J. R.; SALAMUNI, R. Relatório final sobre a geologia, geomorfologia, geotecnia e hidrogeologia da Reservas Naturais Serra do Itaqui e Rio Cachoeira. Curitiba: Sociedade de Pesquisa em Vida Selvagem e Educação Ambiental - SPVS, 2002a. p. 39. Relatório Técnico.

ROCHA, H. O.; CARDOSO, A.; SCHIMIDLIN, D.; ROCHA, A. J. Levantamento de solos da Reserva Natural Serra do Itaqui. Curitiba: Sociedade de Pesquisa em Vida Selvagem e Educação Ambiental SPVS, 2002b. p. 200. Relatório Técnico.

RODERJAN, C. V.; GALVÃO, F.; KUNIYOSHI, Y. S.; KIRSHNER, F. F.; HATSCHBACH, G. G. Levantamento da vegetação da Área de Proteção Ambiental de Guaratuba - APA de Guaratuba. Curitiba: SEMA/UFPR. 1996. Relatório Técnico.

RODRIGUES, R. R.; NAVE, A. G. Heterogeneidade florística das matas ciliares. In: RODRIGUES, R. R.; LEITÃO-FILHO, H. F. Matas ciliares: conservação e recuperação. São Paulo: Editora da Universidade de São Paulo, 2000. p. 45 - 48.

ROSSI, M.; QUEIROZ NETO, J. P. Relação solo/paisagem em região tropicais úmidas: e exemplo da Serra Mar em São Paulo, Brasil. Revista do Departamento de Geografia, v. 14, p. 11 - 23, 2001.

SANTOS, H. G. dos; JACOMINE, P. K. T.; ANJOS, L. H. C. dos; OLIVEIRA, V. A.; OLIVEIRA, J. B.; COELHO, M. R.; LUMBRERAS, J. F.; CUNHA, T. J. F. Sistema Brasileiro de Classificação de Solos. 2 ed. Rio de Janeiro: Embrapa Solos, 2006.

SCARANO, F. R.; RIBEIRO, K. T.; MORAES, L. F. D.; LIMA, H. C. Plant establishment on flooded and unflooded patches of a freshwater swamp forest in southeastern Brazil. Journal of Tropical Ecology, v. 13, n. 6, p. 793 - 803, 1997.

SECRETARIA MEIO AMBIENTE DO ESTADO DO PARANÁ (SEMA). Mapeamento da Floresta Atlântica do Estado do Paraná. Curitiba: PROATLÂNTICA, 2002. Relatório Técnico.

SHEPERD, G. J. Fitopac 1: Manual do usuário. Campinas, SP: UNICAMP, 1994.

SILVA, A. C.; VAN DEN BERG, E.; HIGUCHI, P.; OLIVEIRA-FILHO, A. T.; MARQUES, de SÁ J. G.; APPOLINARIO, V.; PIFANO, D. S.; OGUSUKU, L. M.; NUNES, M. H. Estrutura e diversidade do componente arbóreo de florestas aluviais no sul de Minas Gerais. Revista Brasileira de Biociências, v. 5, n. 1, p. $51-53,2007$.

SOUZA, V. C.; LORENZI, H. Botânica Sistemática - guia ilustrado para identificação das famílias de angiospermas da flora brasileira, baseado em APG II. São Paulo: Instituto Plantarum Nova Odessa, 2005. 
SOCIEDADE DE PESQUISA EM VIDA SELVAGEM E EDUCAÇÃO AMBIENTAL (SPVS). Plano de Manejo da Reserva Natural Serra do Itaqui Curitiba, 2006. Relatório Técnico.

SVOLENSKI, A. C. Aspectos fitossociológicos e pedológicos de três superfícies de agradação do rio Guaraguaçu, litoral do Paraná. 75 f. Dissertação (Mestrado em Engenharia Florestal) - Setor de Ciências Agrárias, Universidade Federal do Paraná, Curitiba, 2000.

SZTUTMAN, M.; RODRIGUES, R. R. O mosaico vegetacional numa área de floresta contínua da planície litorânea, Parque Estadual Campina do Encantado, Pariquera-Açu, SP. Revista Brasileira de Botânica, São Paulo, v. 25, n. 2, p. 161 - 176, 2002.

TEIXEIRA, A. P.; ASSIS, M. A. Caracterização florística e fitossociológica do componente arbustivoarbóreo de uma floresta paludosa no Município de Rio Claro (SP), Brasil. Revista Brasileira de Botânica, São Paulo, v. 28, p. 467 - 476, 2005.

Relação entre heterogeneidade ambiental e distribuição de espécies em uma floresta paludosa no Município de Cristais Paulista, SP, Brasil. Acta Botanica Brasilica, São Paulo, v. 23, p. 843 - 853, 2009.

TONIATO, M. T. Z.; LEITÃO-FILHO, H. F.; RODRIGUES, R. R. Fitossociologia de um remanescente de floresta higrófila (mata de brejo) em Campinas, SP. Revista Brasileira de Botânica, São Paulo, v. 21, n. 2, p. 197 - 210, 1998.

VAN DEN BERG, E.; dos SANTOS, M.; CASTRO, G. C.; FERREIRA, C. A. Estrutura do componente arbóreo de uma floresta de galeria aluvial em Poços de Caldas, MG. Revista Brasileira de Biociências, v. 5 , n. 1 , p. 150 - 152, 2007.

VELOSO, H. P.; KLEIN, R. M. As comunidades e associações vegetais da mata pluvial do Sul do Brasil. V agrupamentos arbóreos da encosta catarinense, situados em sua parte norte. Sellowia, Itajaí, v. 20, p. 53 $126,1968$.

ZILLER, S. R. Análise fitossociológica de caxetais. 101 f. Dissertação (Mestrado em Engenharia Florestal) - Setor de Ciências Agrárias, Universidade Federal do Paraná, Curitiba, 1992. 